\title{
Pengembangan Modul Berbasis Realistic Mathematics Education untuk Pembelajaran Bangun Ruang Sisi Lengkung
}

\author{
Kholifatus Zaqiyah ${ }^{1)}$, Lutfiyah ${ }^{2)}$, Dwi Noviani Sulisawati' ${ }^{3)}$ \\ ${ }^{1,2,3)}$ IKIP PGRI Jember \\ Email: Kholifatuszaqiyah95@gmail.com, azkalutfimh@gmail.com, \\ dwi.moshimoshi@gmail.com
}

\begin{abstract}
This study aims to produce a module based on Realistic Mathematics Education for learning curved side spaces which is implemented in class IX at MTs Baitur Rohmah which aims to describe the process and results of module development in terms of feasibility, practicality, and effectiveness. This research also produced research instruments, namely validation sheets, observation sheets, tests, and questionnaires. The validity of the module was tested by material and media experts. From the field trial, an assessment of the practicality of the module was obtained which was assessed from the results of student response questionnaires and teacher responses. As for the assessment of the effectiveness of the module, it is assessed from tests of student learning outcomes, teacher activities, and student activities. The result is the arrangement of modules based on Realistic Mathematics Education for learning to build curved side spaces that are valid, practical, and effective.
\end{abstract}

Keywords : Development, RME, Module, Build Curved Side Space

\begin{abstract}
ABSTRAK
Penelitian ini bertujuan untuk menghasilkan modul berbasis Realistic Mathematics Education untuk pembelajaran bangun ruang sisi lengkung yang dilaksanakan di kelas IX di MTs Baitur Rohmah yang bertujuan untuk mendeskripsikan proses dan hasil pengembangan modul ditinjau dari aspek kelayakan, kepraktisan, dan keefektifan. Pada penelitian ini dihasilkan pula instrumen penelitian yaitu lembar validasi, lembar observasi, tes, dan angket. Modul diuji kevalidannya oleh ahli materi dan media. Dari uji coba lapangan, didapat penilaian kepraktisan modul yang dinilai dari hasil angket respon siswa dan respon guru. Sedangkan untuk penilaian keefektifan modul dinilai dari tes hasil belajar siswa, aktivitas guru, dan aktivitas siswa. Hasilnya yaitu tersusunnya modul berbasis Realistic Mathematics Education untuk pembelajaran bangun ruang sisi lengkung yang valid, praktis, dan efektif.
\end{abstract}

Kata Kunci : Pengembangan, RME, Modul, Bangun Ruang Sisi Lengkung 


\section{PENDAHULUAN}

Pendidikan memiliki peranan penting untuk mencerdaskan kehidupan bangsa yaitu dengan menyiapkan peserta didik sebagai masa depan bangsa. Namun, dalam pendidikan masih banyak permasalahan yang perlu dibenahi khususnya dalam pembelajaran. Pembelajaran yang perlu diperhatikan adalah pembelajaran matematika, karena banyak hal dalam kehidupan kita yang berhubungan dengan matematika. Pada saat ini banyak siswa yang kesulitan untuk mempelajari dan memahami materi matematika (Rahma, 2012). Pada kelas IX salah satu materi yang dirasa sulit untuk siswa yaitu Bangun Ruang Sisi Lengkung (BRSL). Hal ini dikarenakan materi yang disajikan dalam sumber belajar masih bersifats abstrak. Oleh karena itu, perlu dipikirkan cara untuk mengurangi kesulitan siswa dalam mempelajari materi BRSL. Karena pada tingkat SMP kelas IX siswa sudah bisa berfikir abstrak tetapi tidak maksimal, sebab itu dibutuhkan materi yang bersifat konkret (Runadi, 2014). Untuk meyelesaikan permasalahan tersebut dilakukan pengembangan modul yang disusun dengan mengaitkan kehidupan sehari-hari agar materi lebih bersifat konkret dan siswa dapat mengkonstruksi sendiri ilmu pengetahuannya.

Bahan ajar yaitu semua hal yang dimanfaatkan oleh guru pada kegiatan belajar (Nasiroh, 2014). Sedangakan menurut Nasution (Budiningsih, 2011), modul adalah suatu bahan atau alat yang digunakan dalam pembelajaran yang terstruktur, agar siswa bisa berlatih sendiri dengan atau tanpa fasilitator dan untuk membantu siswa mencapai tujuan pembelajaran. Modul yang dikembangkan harus sesuai dengan kualitas tertentu. Menurut Nienke Nieve (Nasiroh, 2014), modul dikatakan berkualitas jika telah memenuhi tiga aspek yaitu, kepraktisan, kevalidan, dan keefektifan. BSNP (Nasiroh, 2014) menyatakan bahwa pada proses penyusunan modul terdapat sistematika penyusunan modul agar modul yang dikembangkan memenuhi tingkat minimal kevalidan bahan ajar. Ada empat aspek kelayakan yang tercantum dalam BSNP yaitu kelayakan penyajian, bahasa, kegrafisan, dan isi.

Dalam menghasilkan pembelajaran matematika yang baik, maka dalam kegiatan pembelajaran perlu adanya kegiatan belajar yang membiasakan siswa untuk mendapatkan pemahaman melalui pengalamannya sendiri. Sehingga, dibutuhkanlah suatu pendekatan yang dapat membiasakan siswa memperoleh pemahaman atau mengkonstruksi sendiri pengetahuannya. 
Pendekatan pembelajaran matematika yang mampu menghubungkan materi yang abstrak bagi siswa dengan kegidupan sehari-hari adalah Realistic Mathematics Education (RME). RME ini, dapat mempermudah siswa aktif mengkonstruksi sendiri pengetahuannya karena RME dapat menghubungkan materi pembelajaran dengan hal nyata dalam kehidupan yang dapat mudah dipahami oleh siswa (Ratnasari, 2014). Dalam Suzana (2012) ada tiga prinsip dalam menyusun pembelajaran berdasarkan RME yaitu, Guided Re-invention, Didactical Phenomenology, dan Self-delevoped Models. Berdasarkan paparan di atas, maka perlu dikembangkan suatu modul untuk pembelajaran matematika khususnya pada materi BRSL dengan pendekatan RME.

\section{METODE PENELITIAN}

Metode yang digunakan dalam penelitian ini adalah metode penelitian pengembangan dengan menggunakan model Plomp yang terdapat 5 fase (Hobri 2010) yaitu, fase investigasi awal, fase desain, fase realistis/konstruksi, fase tes, evaluasi, dan revisi, dan fase implementasi. Subjek pada penelitian ini adalah siswa kelas IX MTs. Baitur Rohmah yang berjumlah 20 siswa. Untuk mendapatkan data, peneliti menggunakan instrument lembar validasi untuk menilai kevalidan modul yang nantinya dinilai oleh para ahli materi dan ahli media, angket respon siswa dan guru untuk melihat kepraktisan modul, angket observasi aktivitas siswa dan guru serta soal tes untuk melihat keefektifan modul dan wawancara yang dilakukan pada guru matematika di MTs. Baitur Rohmah terkait dengan permasalahan pembelajaran matematika. Kemudian, data yang didapat dianalisis untuk mengetahui bahwa modul sudah dapat dikatakan atau tidak sebagai modul yang valid, praktis, dan efektif.

Analisis data mengukur kevalidan modul, angket respon guru, serta aktivitas guru menggunakan rumus

$$
\bar{x}=\frac{\sum_{i=1}^{n} x_{i}}{n}
$$

Dari hasil perhitungan kemudian mengklasifikasikan dengan tabel rerata skor skala 5. 
Tabel 1. Klasifikasi Rerata Skor Skala 5

\begin{tabular}{cc}
\hline Rerata Skor & Klasifikasi \\
\hline$x>4.2$ & Sangat Baik \\
$3.4<X \leq 4.2$ & Baik \\
$2.6<X \leq 3.4$ & Cukup \\
$1.8<X \leq 2.6$ & Kurang \\
$X \leq 1.8$ & Sangat Kurang \\
\hline
\end{tabular}

Untuk mengukur data angket respon siswa dengan rumus

$$
D p=\frac{n}{N} \times 100 \%
$$

yang kemudian hasil perhitungannya diklasifikasikan pada tabel kriteria angket respon siswa.

Tabel 2. Kriteria Angket Respon Siswa

\begin{tabular}{cc}
\hline Interval & Kriteria \\
\hline $85 \% \leq$ skor $\leq 100 \%$ & Sangat Baik \\
$70 \% \leq$ skor $\leq 84 \%$ & Baik \\
$60 \% \leq$ skor $\leq 69 \%$ & Cukup baik \\
$50 \% \leq$ skor $\leq 59 \%$ & Kurang baik \\
skor $<50$ & Tidak baik \\
\hline
\end{tabular}

Untuk mengukur data aktivitas siswa dengan rumus

$$
P a=\frac{A}{N} \times 100 \%
$$

yang kemudian hasil perhitungannya diklasifikasikan pada Tabel 3 kriteria keaktifan.

Tabel 3. Kriteria Keaktifan

\begin{tabular}{cc}
\hline Persentase & Kriteria \\
\hline$P \geq 80$ & Sangat Aktif \\
$70 \leq P<80$ & Aktif \\
$60 \leq P<70$ & Cukup Aktif \\
$P<60$ & Tidak Aktif \\
\hline
\end{tabular}

Analisis data untuk mengukur tes hasil belajar klasikal dengan rumus

$$
X=\frac{L}{n} \times 100 \%
$$


yang kemudian hasil perhitungannya diklasifikasikan pada tabel penilaian kecakapan akademik.

Tabel 4. Klasifikasi Penilaian Kecakapan Akademik

\begin{tabular}{cc}
\hline Ketuntasan & Klasifikasi \\
\hline$X>80 \%$ & Sangat Baik \\
$60 \%<X \leq 80 \%$ & Baik \\
$40 \%<X \leq 60 \%$ & Cukup \\
$20 \% \leq X \leq 40 \%$ & Kurang \\
$X \leq 20 \%$ & Sangat Kurang \\
\hline
\end{tabular}

\section{HASIL DAN PEMBAHASAN}

\section{Hasil}

Pada fase investigasi awal diketahui bahwa masih banyak siswa mempunyai kemampuan rendah untuk menyelesaikan permasalahan pembelajaran matematika, siswa juga kurang termotivasi untuk aktif dalam pembelajaran bangun ruang sisi lengkung. Oleh karena itu peneliti memilih materi bangun ruang sisi lengkung untuk dijadikan materi penelitian. Berdasarkan hasil wawancara, metode pembelajaran tanya jawab dan ceramah yang hanya digunakan dalam pembelajaran. Selain itu, media yang digunakan hanya berupa LKS dan buku teks guru. Oleh karena itu, peneliti mengembangkan modul berbasis RME yang dapat membantu siswa memahami materi bangun ruang sisi lengkung.

Pada fase desain, dilakukan penyusunan rencana pembelajaran yang pelaksanaan dan tujuan pembelajarannya disesuaikan dengan model atau pendekatan RME. Pada tahap ini pula dilakukan pemilihan media, peneliti memilih bahan ajar berupa modul sebagai media dalam penelitian yang digunakan untuk memudahkan dalam proses pembelajaran. penyajian materi dalam modul disusun semenarik mungkin untuk meningkatkan perhatian dan minat baca siswa, materi disajikan berdasarkan KD, KI yang terdapat dalam silabus, soal tes formatif dan soal evaluasi berbasis Realistic Mathematics Education (RME). Desain awal modul yaitu halaman sampul, kata pengantar, daftar isi, peta konsep, deskripsi modul dan prasyarat, kompetensi inti dan kompetensi dasar, sajian isi modul, isi, evaluasi dan tes formatif, rangkuman, daftar pustaka, glosarium, indeks serta kunci jawaban. 
Pada fase realisasi atau konstruksi, dihasilkan instrument-instrumen yang akan digunakan pada uji coba, serta sebuah modul yang dicetak sesuai dengan Realistic Mathematics Education (RME) dan sesuai dengan desain awal pada fase sebelumnya. Adapun instrumen-instrumen yang dihasilkan yaitu:

a. Lembar Validasi

Aspek yang diukur menggunakan lembar validasi adalah kevalidan RPP, kevalidan modul, kevalidan lembar observasi, kevalidan angket dan kevalidan tes.

b. Lembar Observasi

Aspek yang diukur menggunakan lembar observasi adalah aktivitas siswa dan aktivitas guru.

c. Angket

Aspek yang diukur menggunakan angket adalah respon siswa dan respon guru.

d. Soal Tes

Aspek yang diukur menggunakan soal tes adalah penguasaan materi.

Pada fase tes, evaluasi dan revisi, dilakukan validasi terhadap modul. Modul harus memiliki kriteria layak. Kelayakan modul ditentukan dari hasil validasi modul. Data hasil validasi modul dapat dilihat pada Tabel 5 di bawah ini.

Tabel 5. Hasil Validasi Modul untuk Ahli Materi

\begin{tabular}{lcc}
\hline Indikator Penilaian & Rata-rata & Klasifikasi \\
\hline Kelayakan Isi & 4.06 & Baik \\
$\begin{array}{l}\text { Kelayakan Penyajian } \\
\text { Kesesuaian Modul }\end{array}$ & 4.25 & Sangat Baik \\
$\begin{array}{l}\text { dengan Pendekatan } \\
\text { RME }\end{array}$ & 4.20 & Baik \\
\hline Rata-rata Total & 4.17 & Baik \\
\hline
\end{tabular}

Tabel 6. Hasil Validasi Modul Untuk Ahli Media

\begin{tabular}{lcc}
\hline Indikator Penilaian & Rata-rata & Klasifikasi \\
\hline Kelayakan Kegrafisan & 4.24 & Sangat Baik \\
Kelayakan Penyajian & 4.21 & Sangat Baik \\
Kelayakan Bahasa & 4.17 & Baik \\
\hline Rata-rata Total & 4.21 & Sangat Baik \\
\hline
\end{tabular}


Dari hasil pada Tabel 5 dan Tabel 6, modul yang dikembangkan telah memiliki ratarata nilai diatas minimal modul dapat dikatakan layak. Sehingga dapat disimpulkan bahwa modul yang dihasilkan telah valid atau layak untuk diuji cobakan.

Pada fase terakhir yaitu fase implementasi, dilakukan uji coba modul dengan memberikan modul kepada setiap siswa. Uji coba modul dilakukan untuk mendapatkan data kepraktisan dan keefektifan modul. Untuk kepraktisan modul ditentukan dari hasil analisis angket respon guru dan angket respon siswa. Sedangkan untuk keefektifan modul ditentukan dari hasil analisis aktivitas guru, aktivitas siswa, dan tes hasil belajar. Hasil yang diperoleh ketika uji coba modul adalah data kepraktisan modul dan data keefektifan modul.

Modul dikatakan praktis jika analisis hasil angket respon guru dan angket respon siswa telah mencapai tingkat kepraktisan minimal modul. Adapun hasil analisis angket respon siswa sebagai berikut.

Tabel 7. Analisis Hasil Angket Respon Siswa

\begin{tabular}{cccc}
\hline No Absen & Skor Total & Persentase (\%) & Kriteria \\
\hline 1. & 19 & 95 & Sangat Baik \\
2. & 18 & 90 & Sangat Baik \\
3. & 20 & 100 & Sangat Baik \\
4. & 17 & 85 & Sangat Baik \\
5. & 14 & 70 & Baik \\
6. & 19 & 95 & Sangat Baik \\
7. & 12 & 60 & Cukup Baik \\
8. & 20 & 100 & Sangat Baik \\
9. & 20 & 100 & Sangat Baik \\
10. & 20 & 100 & Sangat Baik \\
11. & 16 & 80 & Baik \\
12. & 19 & 95 & Sangat Baik \\
13. & 19 & 95 & Sangat Baik \\
14. & 20 & 100 & Sangat Baik \\
15. & 14 & 70 & Baik \\
16. & 19 & 95 & Sangat Baik \\
17. & 18 & 90 & Sangat Baik \\
18. & 20 & 100 & Sangat Baik \\
19. & 17 & 85 & Sangat Baik \\
20. & 20 & 100 & Sangat Baik \\
\hline Rata-rata & 453 & 90.6 & Sangat Baik \\
Total & & & \\
\hline & & & \\
\hline
\end{tabular}


Berdasarkan Tabel 7 di atas persentase angket respon siswa mencapai 90.6\%. Sehingga respon siswa telah terpenuhi. Sedangkan untuk hasil analisis angket respon guru rata-rata skor total mencapai 4.50. Berdasarkan analisis hasil angket respons guru dan siswa tersebut, dapat dikatakan bahwa modul yang dikembangkan memiliki kriteria praktis untuk digunakan dalam pembelajaran.

Untuk keefektifan modul, modul dikatakan efektif jika analisis hasil aktivitas siswa minimal memenuhi kriteria aktif, analisis hasil aktivitas guru minimal memenuhi klasifikasi baik, serta persentase tes hasil belajar minimal memenuhi klasifikasi baik pula. Hasil dari aspek diatas dapat dilihat di bawah ini.

Tabel 8. Analisis Hasil Aktivitas Siswa

\begin{tabular}{cccc}
\hline No. Absen & Skor Total & Persentase $(\%)$ & Kriteria \\
\hline 1. & 127 & 88.19 & Sangat Aktif \\
2. & 143 & 99.31 & Sangat Aktif \\
3. & 142 & 98.61 & Sangat Aktif \\
4. & 125 & 86.81 & Sangat Aktif \\
5. & 142 & 98.61 & Sangat Aktif \\
6. & 130 & 90.28 & Sangat Aktif \\
7. & 144 & 100.00 & Sangat Aktif \\
8. & 123 & 85.42 & Sangat Aktif \\
9. & 142 & 98.61 & Sangat Aktif \\
10. & 133 & 92.36 & Sangat Aktif \\
11. & 135 & 93.75 & Sangat Aktif \\
12. & 103 & 71.53 & Aktif \\
13. & 139 & 96.53 & Sangat Aktif \\
14. & 124 & 86.11 & Sangat Aktif \\
15. & 138 & 95.83 & Sangat Aktif \\
16. & 135 & 93.75 & Sangat Aktif \\
17. & 129 & 89.58 & Sangat Aktif \\
18. & 142 & 98.61 & Sangat Aktif \\
19. & 143 & 99.31 & Sangat Aktif \\
20. & 143 & 99.31 & Sangat Aktif \\
\hline & & &
\end{tabular}




Rata-rata Total $\quad 93.13 \quad$ Sangat Aktif

Berdasarkan Tabel 8 di atas, persentase keaktifan siswa mencapai 93.13\%. Sehingga ketuntasan belajar telah terpenuhi. Untuk hasil analisis aktivitas guru dapat dilihat pada Tabel 9 di bawah ini, dari pertemuan ke I, II, dan III memiliki rata-rata skor total yang berada dalam klasifikasi sangat baik.

Tabel 9. Analisis Hasil Aktivitas Guru

\begin{tabular}{lcc}
\hline \multicolumn{1}{c}{ Pertemuan Ke- } & Rata-rata & Klasifikasi \\
\hline Pertemuan I & 4.59 & Sangat Baik \\
Pertemuan II & 4.47 & Sangat Baik \\
Pertemuan III & 4.33 & Sangat Baik \\
\hline
\end{tabular}

Sedangkan untuk hasil tes belajar siswa terdapat 13 siswa mendapat nilai di atas 75. Artinya ketuntasan belajar siswa telah terpenuhi yang secara klasikal telah mencapai $65 \%$. Adapun analisis hasil tes hasil belajar siswa sebagai berikut.

Tabel 10. Analisis Hasil Soal Tes

\begin{tabular}{cccc}
\hline No Absen & KKM & Persentase (\%) & Kriteria \\
\hline 1. & 75 & 80 & Lulus \\
2. & 75 & 90 & Lulus \\
3. & 75 & 80 & Lulus \\
4. & 75 & 78 & Lulus \\
5. & 75 & 85 & Lulus \\
6. & 75 & 65 & Tidak Lulus \\
7. & 75 & 80 & Lulus \\
8. & 75 & 72 & Tidak Lulus \\
9. & 75 & 90 & Lulus \\
10. & 75 & 58 & Tidak Lulus \\
11. & 75 & 72 & Tidak Lulus \\
12. & 75 & 72 & Tidak Lulus \\
13. & 75 & 80 & Lulus \\
14. & 75 & 50 & Tidak Lulus \\
15. & 75 & 47 & Tidak Lulus \\
16. & 75 & 87 & Lulus \\
17. & 75 & 85 & Lulus \\
18. & 75 & 87 & Lulus \\
19. & 75 & 85 & Lulus
\end{tabular}




\begin{tabular}{|c|c|c|}
\hline 20. & 78 & Lulus \\
\hline Lulus & & 13 \\
\hline Tidak Lulus & & 7 \\
\hline Persentase Ketuntasan & & $65 \%$ \\
\hline
\end{tabular}

Berdasarkan hasil analisis hasil aktivitas siswa, aktivitas guru, serta hasil analisis soal tes dapat dikatakan bahwa modul yang dikembangkan memiliki kriteria efektif.

\section{Pembahasan}

Dalam pengembangan ini bertujuan mengembangkan modul berbasis Realistic Mathematics Education untuk pembelajaran bangun ruang sisi lengkung. Setelah melalui validasi modul, modul dikatakan layak untuk dikembangkan berdasarkan dari hasil validasi modul. Berdasarkan hasil analisis siswa didapat bahwa pada tingkat SMP siswa bisa berfikir abstrak, tetapi tidak maksimal maka dari itu perlu adanya materi yang bersifat konkret, siswa juga telah memiliki kemampuan untuk memecahkan masalah (Runadi, 2014). Oleh sebab itu, pada pengembangan modul ini menerapkan model RME sehingga siswa dapat aktif mengkonstruksi sendiri pengetahuannya.

Pada proses pembelajaran dapat dilihat bahwa siswa aktif dalam menggunakan modul dengan mengikuti petunjuk yang telah ada dalam modul. Siswa aktif mengeluarkan pendapatnya dalam memecahkan sebuah masalah yang diberikan, siswa aktif berdiskusi dengan temannya untuk menyampaikan pendapat masingmasing, siswa dapat menemukan rumus luas dan volume bangun ruang sisi lengkung secara mandiri dengan memanfaatkan pengalaman siswa yang berhubungan dengan situasi nyata dan guru membimbing siswa dalam kegiatan menemukan tersebut. Hal diatas sejalan dengan Dahlan (2017) yang menyimpulkan bahwa dengan menggunakan model RME siswa akan aktif mengolah, memanipulasi dan menganalisis informasi yang dapat mengkonstruksi pengetahuannya dalam proses pembelajaran. Kemandirian siswa dalam pembelajaran dengan menggunakan modul tersebut sejalan dengan teori Prastowo (Budiningsih, 2011) yang menyatakan salah satu fungsi modul yaitu meningkatkan kemampuan siswa untuk belajar mandiri tanpa harus bergantung kepada bantuan dari orang lain. 


\section{KESIMPULAN DAN SARAN}

Dalam proses pengembangan modul berbasis Realistic Mathematics Education disimpulkan bahwa terdapat peningkatan hasil belajar siswa yang telah menggunakan modul. Untuk kevalidan modul, modul dikatakan layak digunakan ditinjau dari hasil penilaian aspek-aspek oleh para ahli atau validator. Modul valid dengan rata-rata penilaian oleh ahli materi mencapai 4.17 dan untuk penilaian ahli media mencapai 4.21. Berdasarkan uji coba lapangan modul dikatakan praktis ditinjau dari hasil analisis angket respon siswa yang persentase hasil analisisnya mencapai 90.6\% dan angket respon guru dengan rata-rata mencapai 4.50. Sedangkan untuk keefektifan modul, modul dikatakan efektif ditinjau dari hasil analisis observasi aktivitas siswa yang mencapai $93.13 \%$, observasi aktivitas guru yang berada pada klasifikasi sangat baik, dan hasil tes belajar klasikal siswa mencapai $65 \%$.

Modul yang disusun perlu disesuaikan dengan karakteristik siswa sebagai subjek penelitian. Dalam proses pembelajaran, waktu rencana pembelajaran harus disesuaikan dengan kemampuan siswa agar tujuan pembelajaran dengan menggunakan modul dapat tercapai. Dan sebaiknya contoh dalam materi disesuaikan dengan lingkungan sekitas subjek penelitian.

\section{REFERENSI}

Budiningsih, F. L. (2011). Pengembangan Modul Berbasis Learning Cycle Dengan Penekanan Pada Tahap Engagement Dalam Pembelajaran Sistem Pernafasan Di SMA. Skripsi. Semarang: Universitas Negeri Semarang.

Dahlan, A.H. (2017). Pengembangan Model Pembelajaran Pendidikan Matematika Realistik Indonesia (PMRI) Untuk Meningkatkan Ketertarikan Belajar Matematika. Tesis. Yogyakarta: Universitas Sanata Dharma Yogyakarta.

Hobri. (2010). Metodologi Penelitian Pengembangan. Jember: Pena Salsabila

Nasiroh, D. (2014). Pengembangan Modul Dengan Pendekatan Kontekstual Pada Materi Barisan dan Deret Untuk Siswa SMP Terbuka kelas IX. Skripsi. Yogyakarta: Universitas Negeri Yogyakarta.

Prastowo, A. (2012). Panduan Kreatif Membuat Bahan Ajar Inovatif; Menciptakan Metode Pembelajaran Yang Menarik Dan Menyenangkan. Yogyakarta: Diva Press. 
Ratnasari, R. E. (2014). Pengaruh Pendekatan Realistic Mathematics Education (RME) Terhadap Hasil Belajar Materi Dimensi Tiga Siswa kelas X MA Unggulan Bandung Tulungagung Tahun Pelajaran 2013/2014. Skripsi: STAIN Tulungagung.

Runadi, Taruga. (2014). Pengembangan Perangkat Pembelajaran Matematika Bangun Ruang Sisi Lengkung Dengan Model Pembelajaran Berbasis Masalah. Skripsi. Yogyakarta: Universitas Negeri Yogyakarta.

Suzana, A. (2012). Pengembangan Modul Matematika Program Bilingual Pada Materi Segiempat Dengan Pendekatan PMRI Untuk Siswa SMP kelas VII Semester Genap. Skripsi. Yogyakarta: Universitas Negeri Yogyakarta. 